\title{
Postnatal parental smoking: an important risk factor for SIDS
}

\author{
Germaine Liebrechts-Akkerman • Oscar Lao • Fan Liu • Bregje E. van Sleuwen • \\ Adèle C. Engelberts • Monique P. L'Hoir • Henning W. Tiemeier • Manfred Kayser
}

Received: 6 November 2010 / Accepted: 15 February 2011 /Published online: 15 March 2011

(C) The Author(s) 2011. This article is published with open access at Springerlink.com

\begin{abstract}
Background Sudden infant death syndrome (SIDS) is the unexpected death of an infant that remains unexplained after a thorough investigation of the circumstances, family history, paediatric investigation and complete autopsy. In Western society, it is the leading cause of post-neonatal death below 1 year of age. In the Netherlands, the SIDS incidence is very low, which offers opportunities to assess the importance of old and new environmental risk factors. For this purpose, cases were collected through pathology departments and the
\end{abstract}

Germaine Liebrechts-Akkerman, Bregje E. van Sleuwen, Adèle C. Engelberts, Monique P. L'Hoir: the working group on cot death of the Dutch Paediatrician Association

G. Liebrechts-Akkerman $\cdot$ O. Lao $\cdot$ F. Liu $\cdot$ M. Kayser

Department of Forensic Molecular Biology, Erasmus MC

University Medical Center Rotterdam,

2040, 3000 CA Rotterdam, The Netherlands

B. E. van Sleuwen • M. P. L'Hoir

Netherlands Paediatric Surveillance Unit,

TNO Prevention and Health,

2215, 2301 CE Leiden, The Netherlands

A. C. Engelberts

Department of Paediatrics, Orbis Medical Center,

5500, 6130 MB Sittard, The Netherlands

H. W. Tiemeier

Department of Epidemiology and Child and Adolescent

Psychiatry, Erasmus MC University Medical Center Rotterdam,

2040, 3000 CA Rotterdam, The Netherlands

G. Liebrechts-Akkerman $(\bowtie)$

Department of Clinical Pathology (JNI),

Erasmus MC University Medical Center Rotterdam, 2040, 3000 CA Rotterdam, The Netherlands

e-mail: g.akkerman@erasmusmc.nl working group on SIDS of the Dutch Paediatrician Foundation. A total of 142 cases were included; these occurred after the parental education on sleeping position (1987), restricted to the international age criteria and had no histological explanation. Agematched healthy controls $(N=2,841)$ came from a survey of the Netherlands Paediatric Surveillance Unit, completed between November 2002 and April 2003. A multivariate analysis was performed to determine the risk factors for SIDS, including sleeping position, antenatal maternal smoking, postnatal parental smoking, premature birth, gender, lack of breastfeeding and socio-economic status. Postnatal smoking was identified as an important environmental risk factor for SIDS (OR one parent $=2.5[1.2$, $5.0]$; both parents $=5.77[2.2,15.5]$; maternal $=2.7[1.0$, 6.4]; paternal $=2.4[1.3,4.5])$ as was prone sleeping (OR put prone to sleep $=21.5[10.6,43.5]$; turned prone during sleep $=100[46,219])$. Premature birth was also significantly associated with SIDS (OR=2.4 $[1.2,4.8])$.

Conclusion Postnatal parental smoking is currently a major environmental risk factor for SIDS in the Netherlands together with the long-established risk of prone sleeping.

Keywords Sudden infant death · SIDS · Case-control study - Environmental risk factors · Prone sleeping · Parental smoking $\cdot$ Breastfeeding $\cdot$ Premature birth

\section{Introduction}

Sudden infant death syndrome (SIDS) is the sudden and unexpected death of a child below 1 year of age that remains unexplained after a thorough investigation of the circumstances, family history, a paediatric examination and a full autopsy [12]. Over the last 20 years, several 
risk factors for SIDS were discovered such as male gender, premature birth, prone sleeping, fluffy/stuffed bedding and tobacco smoking of the parents, whereas breastfeeding, room sharing, sleeping sack and dummy use were found to have a protective effect $[1,4,9-11,13-$ $15,21,23,24]$. It is assumed that prematurely born children are more vulnerable because some organ systems are not fully developed yet [10]; prone sleeping and fluffy/ stuffed bedding pose the risk of $\mathrm{CO}_{2}$ rebreathing, which results in low oxygen levels and eventually death [12]; the risk of tobacco smoke for young children is often interpreted as harmful to the development of the unborn child when the mother smokes during pregnancy $[1,4,10$, 11, 15, 21]. In many Western countries, education programmes and campaigns were started after several environmental risk factors of SIDS were discovered, most importantly prone sleeping. These programmes resulted in a strong decline of SIDS [1, 4, 17], supporting the idea that those factors are contributing causally to SIDS.

The Netherlands has the lowest incidence of SIDS in the Western world with 0.078 per 1,000 living births in 2007 [7]. However, autopsy is not always performed [9, 14]. Thus, this rate is likely to be an overestimation and would be lower if international criteria for SIDS [12] were applied more strictly. On the other hand, cases in which a certain diagnosis is assumed without an autopsy might actually be SIDS. The incidence of SIDS in the Netherlands declined dramatically after acknowledgement of prone sleeping as a risk factor in 1987 and inclusion of this knowledge in the national parental education programme (Fig. 1) [9]. However, after 20 years of educating parents, about 15 young infants still die suddenly and unexpectedly every year without any explanation after a careful investigation of

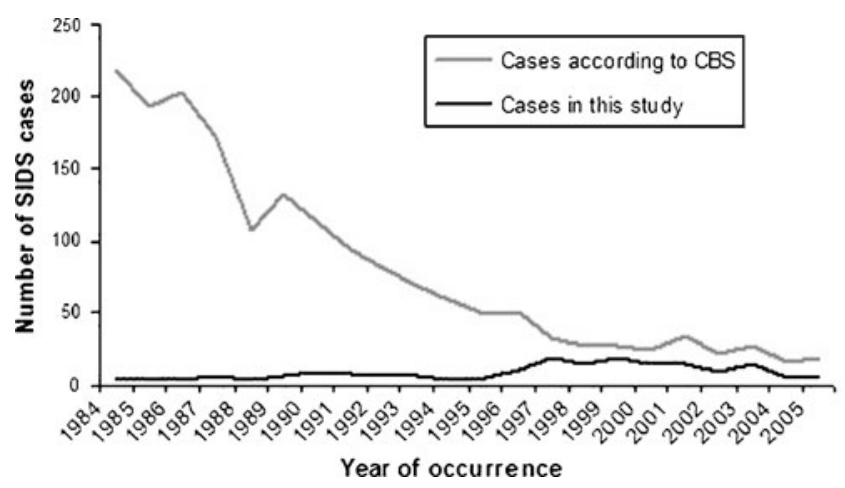

Fig. 1 Distribution of cases of SIDS in the Netherlands over the last 25 years with all cases known to the Central Bureau of Statistics of the Netherlands depicted as grey line and the cases included in the present study as black line. Note the decline of SIDS cases according to Central Bureau of Statistics after 1987 when parental education programmes on SIDS acknowledged prone sleeping as a risk factor and the increase of cases collected as part of our study in 1996 when the Dutch National Cot-Death Society was founded and started to collect information circumstances and paediatric and pathologic investigations. In an effort to better understand the aetiology, we designed a retrospective Dutch case-control study. Previously, we conducted a histology review (Liebrechts-Akkerman et al., submitted for publication) on the cases used in this study, allowing us to define four subcategories of SIDS, which were tested here for specific environmental risk factors.

\section{Patients and methods}

SIDS cases collection and inclusion criteria

We collected 200 cases classified as SIDS by pathologists dating from 1984 up until 2005. Case collection methods have previously been published as was the histological review of the cases (Liebrechts-Akkerman et al., submitted for publication). In summary: firstly, a computer-based search using the national pathology registry (PALGA) was performed [6]; secondly, the Dutch Paediatrician Association (Landelijke Werkgroep Wiegendood, LWW) was asked to provide an anonymous list of all reported cases that were autopsied across the Netherlands between 1996 (the year the LWW was founded) and 2005. Subsequently, all pathology departments involved, including that of the Netherlands Forensic Institute, were contacted. Therefore, almost all SIDS cases recorded in the Netherlands after 1996 that have been autopsied are included in this study. Unfortunately, no data exist on the total number of autopsied cases before 1996. Parental education campaigns at well baby clinics, to inform parents on prone sleeping as major risk factor, started in 1987; therefore, all cases before $1987(n=19)$ were excluded. Unlike the internationally accepted definition for SIDS, which uses a range from 3 weeks up to 1 year [12], LWW accepts an age range from birth up to 2 years [9]. To be able to compare our findings with those of other studies and because we found bronchopneumonia in all cases of babies who died before 1 week of age (Liebrechts-Akkerman et al., submitted for publication), we excluded all cases of babies younger than 1 week and over 1 year of age (36 cases). Finally, the cases in which we found a reasonable cause of death during histological review (Liebrechts-Akkerman et al., submitted for publication), other than infection, which is allowed in the SIDS II category [12], were also excluded (an additional three cases, causes of death were metabolic disorder and aspiration). This left 142 cases for analyses. The environmental data used were derived from anonymous pathology reports and anonymous questionnaires filled in at structured interviews with the parents by LWW (57.7\%). The mean time between time of death and the interview was 42 days. This study was carried out with appropriate ethical approval as described previously (Liebrechts-Akkerman et al., submitted for publication). 
Sampling of controls

The control group was provided by the Netherlands Paediatric Surveillance Unit and consisted of 2,913 infants between 0 and 35 months of age from across the Netherlands. The interviews, which were held between November 2002 and April 2003 at well baby clinics, aimed infants till up to 6 months of age; however, 34 exceeded 1 year of age. The data were previously used for a surveillance of SIDS risk factors in the Netherlands [22]. All controls younger than 1 week and older than 1 year of age were excluded $(n=72)$.

Statistical analysis and definitions of risk factors

The relationship between risk factors and SIDS was estimated by logistic regression analysis; all covariates were adjusted by means of multivariate analysis, odds ratios (ORs) and 95\% confidence intervals (CIs) were calculated. The following factors were included in the multivariate analysis: gender, sleeping position, premature birth (pregnancy duration $<38$ weeks), breastfeeding, prenatal maternal and postnatal parental smoking, ethnical origin and education level of the parents. Sleeping position was divided in non-prone sleeping (indicator) and primary and secondary prone sleeping, respectively. Primary prone means being put to sleep in prone position, and secondary prone means being put to sleep in any other position and subsequently found prone. The controls were asked about the usual and last night's sleeping habits; the later was used in this study. Postnatal parental smoking was divided in no postnatal parental smoking (indicator), one parent smoking and both parents postnatal smoking in the first analysis, and in the second analysis maternal and paternal postnatal smoking were treated as separate covariates. Ethnic origin of the parents was divided in both parents being European (indicator), one parent being European and both parents being non-European. Breastfed babies in the case group were usually still being breastfed when they died; therefore, the influence of the duration of breastfeeding could not be established. Having started breastfeeding was taken as a binary factor in the analysis. The education level of the parents was divided into both highly educated (indicator), one highly educated and none highly educated. A parent was considered as not highly educated if he/she had only attended (between brackets the Dutch counterpart): elementary or primary school (basisschool), secondary education or junior high (MAVO/LBO), community college (MBO). A parent was considered highly educated if he/she had attended: secondary education A levels/grammar school or high school (HAVO/ VWO); bachelor studies or college (HBO); university-master degree or higher (WO). The analysis were repeated on categories according to our histological findings (Liebrechts-Akkerman et al., submitted for publication): genuine SIDS, no findings that might have had an influences on survival; SIDS with minor infections, e.g. laryngitis, urine bladder infection, etc.; SIDS+, a non-infectious disease that might have contributed to death; major infection SIDS, e.g. bronchopneumonia. Finally, the analyses were repeated on four categories defined by year of death: 1987-1990, 1991-1995, 1996-2000, 2001-2005. For statistical analyses, we used SPSS for Windows, version 15.0 (SPSS Inc., Chicago, IL, USA).

\section{Results}

All results were obtained from multivariate analyses, which included 142 cases and 2,841 controls. There was no statistically significant difference in age between cases (mean 140 days [16-338]; SD 78.5) and controls (mean 99 days [8-350]; SD 51.1) when considering all SIDS cases together compared to the controls. No differences in the male-female ratio were observed ( $p$-value ranging from 0.19 to 0.99 ; Tables $1,2,3,4,5,6$, and 7) in any of the analyses. In none of the analyses were the education level of the parents ( $p$-value varying from 0.09 till 0.90 ), their ethnical origin ( $p$-value varying from 0.17 till 1.0$)$ or the lack of breastfeeding ( $p$-value varying from 0.13 till 0.56 ) statistically significant (Tables 1, 2, 3, 4, 5, 6, and 7).

Prone sleeping position was the most significant risk factor for SIDS in our study ( $p$-value $<0.001$ in all analyses; OR for primary varying from 14.4 up to 49.9 ; OR for secondary varying from 80.9 till 173.8; Tables 1 , $2,3,4,5,6$, and 7). There were significantly more prematurely born cases than controls $(\mathrm{OR}=2.5,95 \% \mathrm{CI}=$ $[1.2,5.0], p$-value $=0.01$; Table 1). Furthermore, postnatal parental smoking was found to be a major risk factor; the OR for one parent smoking vs. non-smoking was 2.5 $(95 \% \mathrm{CI}=[1.2,5.0], p$-value $=0.011$; Table 1$)$ and the OR for both parent smoking vs. non-smoking was $5.8(95 \%$ $\mathrm{CI}=[2.2,15.5], p$-value $=0.001$; Table 1$)$. When divided in maternal and paternal postnatal smoking, the latter had a higher statistical significance although with a slightly lower OR (maternal postnatal smoking $\mathrm{OR}=2.7[1.0,6.4]$, $p$-value $=0.04$; paternal $\mathrm{OR}=2.4[1.3,4.5], p$-value $=$ 0.006 ; Table 1). No statistically significant effect of prenatal maternal smoking ( $p$-values $=0.5$ and 0.7 ; Table 1 ) was observed. Subsequently, we excluded all cases and controls where the mother had smoked during pregnancy from the analysis (Tables 2 and 3). This resulted in premature birth and postnatal maternal smoking being no longer significantly associated with SIDS ( $p$-values 0.11 and 0.41 , respectively). However, postnatal smoking of one parent vs. none $(\mathrm{OR}=2.5[1.2,5.3], p$-value $=0.02)$, both parents vs. none $(\mathrm{OR}=4.5[1.1,19.4], p$-value $=0.04)$ and the father $(\mathrm{OR}=2.7[1.3,5.6], p$-value 0.01$)$ remained significantly associated with SIDS. 
Table 1 Association of SIDS $(n=142)$ with covariates compared to healthy, age-matched Dutch controls $(n=2,841) . P$-values and odds ratios for the entire case group. $P$-values calculated with two-tailed Fishers' exact test, OR and $95 \%$ CI for OR of the binary logistic regression of all covariates. Multivariate analysis 1 is with postnatal smoking considered none; one or both parents smoking postnatal as one covariate. Multivariate analysis 2 is with postnatal smoking considered maternal or paternal postnatal smoking as two separate covariates

\begin{tabular}{|c|c|c|c|c|c|c|c|c|c|c|c|c|c|}
\hline \multirow[t]{3}{*}{ Covariate } & \multirow{2}{*}{\multicolumn{2}{|c|}{ Cases }} & \multirow{2}{*}{\multicolumn{2}{|c|}{ Controls }} & \multirow{3}{*}{$\begin{array}{l}\text { Univariate } \\
\text { analysis } \\
P \text {-value }\end{array}$} & \multicolumn{4}{|c|}{ Multivariate analysis 1} & \multicolumn{4}{|c|}{ Multivariate analysis 2} \\
\hline & & & & & & \multirow[b]{2}{*}{$P$-value } & \multirow[b]{2}{*}{ OR } & \multicolumn{2}{|c|}{$95 \% \mathrm{CI}$ interval } & \multirow[b]{2}{*}{$P$-value } & \multirow[b]{2}{*}{ OR } & \multicolumn{2}{|c|}{$95 \%$ CI interval } \\
\hline & $N$ & $\%$ & $N$ & $\%$ & & & & Lower & Upper & & & Lower & Upper \\
\hline \multicolumn{14}{|l|}{ Gender } \\
\hline Female & 61 & 43 & 1,403 & 49 & & & & & & & & & \\
\hline Male & 81 & 57 & 1,434 & 51 & 0.44 & 0.97 & 0.99 & 0.56 & 1.76 & 0.86 & 0.95 & 0.53 & 1.69 \\
\hline \multicolumn{14}{|l|}{ Premature } \\
\hline No & 76 & 74 & 2,492 & 89 & & & & & & & & & \\
\hline Yes & 27 & 26 & 317 & 11 & $<0.001$ & 0.013 & 2.41 & 1.20 & 4.81 & 0.011 & 2.45 & 1.23 & 4.89 \\
\hline \multicolumn{14}{|l|}{ Parental education } \\
\hline Both high & 17 & 24 & 797 & 30 & & & & & & & & & \\
\hline One high & 13 & 18 & 827 & 31 & 0.031 & 0.87 & 1.06 & 0.51 & 2.21 & 0.88 & 1.06 & 0.51 & 2.20 \\
\hline Both low & 41 & 58 & 1,022 & 39 & 0.003 & 0.32 & 0.65 & 0.28 & 1.51 & 0.32 & 0.65 & 0.28 & 1.51 \\
\hline \multicolumn{14}{|l|}{ Parental ethnicity } \\
\hline Both European & 73 & 81 & 2,130 & 83 & & & & & & & & & \\
\hline One European & 8 & 9 & 341 & 13 & 0.81 & 0.96 & 0.98 & 0.41 & 2.35 & 0.98 & 0.99 & 0.41 & 2.37 \\
\hline Both non-European & 9 & 10 & 99 & 4 & 0.81 & 0.35 & 0.42 & 0.07 & 2.53 & 0.36 & 0.44 & 0.07 & 2.60 \\
\hline \multicolumn{14}{|l|}{ Started breastfeeding } \\
\hline Yes & 50 & 60 & 2,264 & 80 & & & & & & & & & \\
\hline No & 33 & 40 & 559 & 20 & 0.002 & 0.19 & 0.65 & 0.35 & 1.24 & 0.25 & 0.68 & 0.36 & 1.31 \\
\hline \multicolumn{14}{|l|}{ Prone sleeping } \\
\hline No & 52 & 46 & 2,715 & 96 & & & & & & & & & \\
\hline Primary & 36 & 32 & 83 & 3 & $<0.001$ & $<0.001$ & 21.48 & 10.62 & 43.46 & $<0.001$ & 19.97 & 9.75 & 40.93 \\
\hline Secondary & 24 & 21 & 27 & 1 & $<0.001$ & $<0.001$ & 100.5 & 45.96 & 219.6 & $<0.001$ & 100.6 & 46.26 & 218.8 \\
\hline \multicolumn{14}{|c|}{ Prenatal maternal smoking } \\
\hline No & 50 & 65 & 2,438 & 87 & & & & & & & & & \\
\hline Yes & 27 & 35 & 376 & 13 & $<0.001$ & 0.48 & 1.36 & 0.58 & 3.16 & 0.72 & 1.20 & 0.46 & 3.15 \\
\hline \multicolumn{14}{|c|}{ Postnatal parental smoking } \\
\hline None & 28 & 33 & 1,895 & 67 & & & & & & & & & \\
\hline One & 30 & 36 & 653 & 23 & 0.008 & 0.011 & 2.49 & 1.24 & 5.03 & & & & \\
\hline Both & 26 & 31 & 260 & 9 & $<0.001$ & 0.001 & 5.77 & 2.15 & 15.53 & & & & \\
\hline Postnatal maternal sn & king & & & & & & & & & & & & \\
\hline No & 47 & 57 & 2,431 & 86 & & & & & & & & & \\
\hline Yes & 36 & 43 & 396 & 14 & $<0.001$ & & & & & 0.04 & 2.67 & 1.04 & 6.35 \\
\hline Postnatal paternal sm & king & & & & & & & & & & & & \\
\hline No & 35 & 44 & 2,026 & 72 & & & & & & & & & \\
\hline Yes & 45 & 56 & 792 & 28 & $<0.001$ & & & & & 0.006 & 2.41 & 1.28 & 4.53 \\
\hline
\end{tabular}

All analyses were first repeated on two of the four histological subgroups previously defined (LiebrechtsAkkerman et al., submitted for publication): genuine SIDS (no findings that had any influences on survival, $n=100$ ) and minor infections (e.g. laryngitis, urinary bladder infection, etc., $n=28$ ) (Tables 4 and 5). SIDS+ (noninfectious disease that might have contributed to death, $n=6$ ) and major infection SIDS (e.g. bronchopneumonia, $n=8$ ) were excluded from analysis because of the low case number. No statistically significant association was found between gender, lack of breastfeeding, parental education or ethnical origin and any of the histologically defined SIDS subgroups. Prone sleeping position, either primary or secondary, was significant in both subgroups (OR varying between 14.4 and 49.9 for primary and between 100.0 and 173.8 for secondary prone sleeping, $p$-value $<0.001$ ) as was smoking of both parents $(\mathrm{OR}=5.0, p$-value $=0.007$ and $\mathrm{OR}=$ 6.8, $p$-value $=0.05$, respectively; Table 4). In contrast, 
Table 2 Association of SIDS $(n=50)$ with covariates compared to healthy Dutch controls $(n=2,438)$; included were only cases and controls where it was reported that no maternal prenatal smoking is involved. $P$-values and odds ratios for the entire case group. $P$-values calculated with two-tailed Fishers' exact test, OR and 95\% CI for OR of the binary logistic regression of all covariates. Prone sleeping 1 is primary prone sleeping; prone sleeping 2 is secondary prone sleeping; supine sleeping is indicator. Postnatal smoking 1 is one parent smokes; postnatal smoking 2 is both parents smoke; no postnatal parental smoking is indicator. Education parents 1 is both low; education parents 2 is one low; both high educated is indicator. Ethnical origin parents 1 is one European Caucasian, one nonEuropean Caucasian; ethnical origin parents 2 is both non-European Caucasian; both European Caucasian is indicator

\begin{tabular}{|c|c|c|c|c|c|c|c|c|}
\hline \multirow[t]{3}{*}{ Covariate } & \multicolumn{4}{|l|}{1} & \multicolumn{4}{|l|}{2} \\
\hline & \multirow[t]{2}{*}{ Significance } & \multirow[t]{2}{*}{ Odds ratio } & \multicolumn{2}{|c|}{$95 \% \mathrm{CI}$ for $\mathrm{OR}$} & \multirow[t]{2}{*}{ Significance } & \multirow[t]{2}{*}{ Odds ratio } & \multicolumn{2}{|c|}{$95 \% \mathrm{CI}$ for OR } \\
\hline & & & Lower & Upper & & & Lower & Upper \\
\hline Prone sleeping & $<0.001$ & 19.3 & 7.73 & 48.1 & $<0.001$ & 146.8 & 61.1 & 352.8 \\
\hline Postnatal smoking & 0.018 & 2.50 & 1.17 & 5.34 & 0.041 & 4.54 & 1.06 & 19.4 \\
\hline Premature birth & 0.11 & 2.06 & 0.86 & 4.95 & & & & \\
\hline Gender & 0.62 & 1.20 & 0.59 & 2.44 & & & & \\
\hline Education parents & 0.77 & 1.13 & 0.49 & 2.62 & 0.09 & 0.41 & 0.15 & 1.15 \\
\hline Ethnical origin parents & 0.56 & 1.39 & 0.47 & 4.12 & 0.79 & 0.75 & 0.09 & 6.15 \\
\hline Lack of breastfeeding & 0.27 & 0.63 & 0.27 & 1.44 & & & & \\
\hline
\end{tabular}

postnatal smoking of one parent, the father separately, and prenatal maternal smoking were not. However, postnatal maternal smoking was borderline significantly associated with genuine SIDS ( $p$-value $=0.05$, OR $3.0[0.99,8.7]$; Table 5). Premature birth was significantly associated with minor infection cases $(\mathrm{OR}=3.7, p$-value $=0.04$; Tables 4 and 5) but not with genuine SIDS ( $p$-value $=0.2$ ).

Finally, all analyses were repeated considering the years of death (Tables 6 and 7). Two categories, 1987-1990 and 1991-1995, were excluded from analysis because of the very low case number with complete data (Table 8 ). For the remaining two categories, 1996-2000 and 2001-2005, no statistically significant association was found with respect to gender, breastfeeding, parental education or ethnical origin and SIDS. Prone sleeping position, either primary or secondary, was significant in both categories (OR for primary prone sleeping ranges between 17.8 and 22.6 and for secondary between 80.9 and 115.7, $p$-value <0.001). Premature birth was only significantly associated with SIDS cases that died between 2001 and $2005(n=37, p$-value $=$ 0.01, OR differs between 3.3 and 3.5; Tables 6 and 7, respectively). Postnatal smoking of one parent versus none was not significant in 1996-2000 ( $p$-value $=0.07)$ and borderline significant in 2001-2005 ( $p$-value $=0.05$ ). Postna-
Table 3 Association of SIDS $(n=50)$ with covariates compared to healthy Dutch controls $(n=2,438)$; included were only cases and controls where it was reported that no maternal prenatal smoking is involved. $P$-values and odds ratios for entire case group. $P$-values calculated with two-tailed Fishers' exact test, OR and 95\% CI for OR of the binary logistic regression of all covariates. Prone sleeping 1 is primary prone sleeping; prone sleeping 2 is secondary prone sleeping; supine sleeping is indicator. Education parents 1 is both low; education parents 2 is one low; both high educated is indicator. Ethnical origin parents 1 is one European Caucasian, one nonEuropean Caucasian; ethnical origin parents 2 is both non-European Caucasian; both European Caucasian is indicator

\begin{tabular}{|c|c|c|c|c|c|c|c|c|}
\hline \multirow[t]{3}{*}{ Covariate } & \multicolumn{4}{|l|}{1} & \multicolumn{4}{|l|}{2} \\
\hline & \multirow[t]{2}{*}{ Significance } & \multirow[t]{2}{*}{ Odds ratio } & \multicolumn{2}{|c|}{$95 \% \mathrm{CI}$ for $\mathrm{OR}$} & \multirow[t]{2}{*}{ Significance } & \multirow[t]{2}{*}{ Odds ratio } & \multicolumn{2}{|c|}{$95 \% \mathrm{CI}$ for $\mathrm{OR}$} \\
\hline & & & Lower & Upper & & & Lower & Upper \\
\hline Prone sleeping & $<0.001$ & 19.7 & 7.9 & 49.2 & $<0.001$ & 147.2 & 61.1 & 354.3 \\
\hline Premature birth & 0.11 & 2.07 & 0.86 & 4.97 & & & & \\
\hline Gender & 0.62 & 1.20 & 0.59 & 2.44 & & & & \\
\hline Education parents & 0.78 & 1.13 & 0.49 & 2.61 & 0.10 & 0.42 & 0.15 & 1.17 \\
\hline Ethnical origin parents & 0.56 & 1.38 & 0.46 & 4.10 & 0.77 & 0.73 & 0.09 & 6.01 \\
\hline Lack of breastfeeding & 0.27 & 0.63 & 0.27 & 1.43 & & & & \\
\hline Maternal postnatal smoking & 0.41 & 1.2 & 0.49 & 5.79 & & & & \\
\hline Paternal postnatal smoking & 0.01 & 2.70 & 1.26 & 5.60 & & & & \\
\hline
\end{tabular}


Table 4 Association of two histologically defined categories of SIDS with covariates compared to healthy, age-matched Dutch controls $(n=$ 2,841). $P$-values and odds ratios for the two largest SIDS categories defined by histological findings; genuine SIDS, no findings that might have had any influences on survival; SIDS with minor infections, e.g. laryngitis, urine bladder infection, etc. $P$-values calculated with twotailed Fishers' exact test, OR and $95 \%$ CI for OR of the binary logistic regression of all covariates. Prone sleeping 1 is primary prone sleeping; prone sleeping 2 is secondary prone sleeping; supine sleeping is indicator. Postnatal smoking 1 is one parent smokes; postnatal smoking 2 is both parents smoke; no postnatal parental smoking is indicator. Education parents 1 is both low; education parents 2 is one low; both high educated is indicator. Ethnical origin parents 1 is one European Caucasian, one non- European Caucasian; ethnical origin parents 2 is both non-European Caucasian; both European Caucasian is indicator

\begin{tabular}{|c|c|c|c|c|c|c|c|c|}
\hline \multirow[t]{3}{*}{ Covariate } & \multicolumn{4}{|l|}{1} & \multicolumn{4}{|l|}{2} \\
\hline & \multirow[t]{2}{*}{ Significance } & \multirow[t]{2}{*}{ Odds ratio } & \multicolumn{2}{|c|}{ 95.0\% C.I. for OR } & \multirow[t]{2}{*}{ Significance } & \multirow[t]{2}{*}{ Odds ratio } & \multicolumn{2}{|c|}{$95.0 \%$ C.I. for $\mathrm{OR}$} \\
\hline & & & Lower & Upper & & & Lower & Upper \\
\hline \multicolumn{9}{|l|}{ Genuine SIDS $(n=100)$} \\
\hline Prone sleeping & $<0.001$ & 17.1 & 6.99 & 41.9 & $<0.001$ & 102.1 & 41.4 & 251.7 \\
\hline Postnatal smoking & 0.143 & 1.91 & 0.80 & 4.53 & 0.007 & 5.02 & 1.56 & 16.16 \\
\hline Premature birth & 0.21 & 1.75 & 0.73 & 4.18 & & & & \\
\hline Gender & 0.39 & 1.36 & 0.68 & 2.71 & & & & \\
\hline Education parents & 0.28 & 1.71 & 0.65 & 4.47 & 0.73 & 1.21 & 0.42 & 3.44 \\
\hline Ethnical origin parents & 0.18 & 1.85 & 0.75 & 4.53 & 0.35 & 0.32 & 0.03 & 3.38 \\
\hline Lack of breastfeeding & 0.13 & 0.56 & 0.26 & 1.18 & & & & \\
\hline Maternal prenatal smoking & 0.67 & 1.75 & 0.45 & 3.46 & & & & \\
\hline \multicolumn{9}{|c|}{ SIDS with minor infection $(n=28)$} \\
\hline Prone sleeping & $<0.001$ & 49.9 & 13.2 & 188.5 & $<0.001$ & 153.6 & 32.8 & 720.4 \\
\hline Postnatal smoking & 0.14 & 2.86 & 0.70 & 11.6 & 0.045 & 6.76 & 1.04 & 43.9 \\
\hline Premature birth & 0.045 & 3.66 & 1.03 & 12.9 & & & & \\
\hline Gender & 0.19 & 0.43 & 0.12 & 1.51 & & & & \\
\hline Education parents & 0.90 & 1.10 & 0.23 & 5.22 & 0.78 & 0.78 & 0.13 & 4.55 \\
\hline Ethnical origin parents & 1.00 & 0.00 & & & 1.00 & 0.00 & & \\
\hline Lack of breastfeeding & 0.53 & 0.67 & 0.19 & 2.37 & & & & \\
\hline Maternal prenatal smoking & 0.52 & 1.61 & 0.37 & 7.02 & & & & \\
\hline
\end{tabular}

tal smoking of both parents was statistically significant in both groups $(\mathrm{OR}=5.4, p$-value $=0.009$ in 1996-2000 and $\mathrm{OR}=6.6, p$-value $=0.01$ in 2001-2005). Interestingly, maternal postnatal smoking was borderline significantly associated with SIDS cases between 1996 and $2000(p$-value=0.06) but did not even nearly reach significance in the cases between 2001 and 2005 ( $p$-value $=0.2$ ). However, paternal postnatal smoking was not statistically significant in 1996-2000 ( $p$-value $=0.07)$ but was in 2001-2005 $(p$-value $=0.02, \mathrm{OR}=$ 3.2 [1.2-8.5]; Table 7). Prenatal smoking of the mother was not found as statistically significantly associated neither of the subgroups ( $p$-values range between 0.47 in 1996-2000 to 0.98 in 2001-2005; Table 6).

\section{Discussion}

Several risk factors for SIDS have been discussed for over 20 years [1, 4, 9-11, 13-15, 21, 23, 24], including prone sleeping, premature birth, male gender, the lack of breastfeeding and parental smoking. In the present retro- spective study, we have conducted a case-control study with SIDS cases and healthy controls from the Dutch population and estimated the association of these environmental factors with this phenotypic trait. Our dataset comprises a considerably large number of cases and valuable information about parental socio-economic status. However, despite our efforts, information on all considered risk factors for all the cases was often incomplete (Table 8). Furthermore, SIDS cases were collected over a much broader time period than controls. This could introduce a bias in our results as the number of smoking people has declined over the years and was higher prior to the collection of controls. Nevertheless, we hope to overcome part of this bias by means of a separate analysis on the year quartiles.

Our results showed that some of the previously known risk factors are still significantly associated with SIDS in the Dutch population despite the parental education policy that started over 20 years ago. Prone sleeping of the baby, both being placed prone by the parents or turning in that position, remains the most important risk factor in line with 
Table 5 Association of two histological defined categories of SIDS with covariates compared to healthy, age-matched Dutch controls $(n=$ 2,841). $P$-values and odds ratios for the two largest SIDS categories defined by histological findings; genuine SIDS, no findings that might have had any influences on survival; SIDS with minor infections, e.g. laryngitis, urine bladder infection, etc. $P$-values calculated with twotailed Fishers' exact test, OR and 95\% CI for OR of the binary logistic regression of all covariates. Prone sleeping 1 is primary prone sleeping; prone sleeping 2 is secondary prone sleeping; supine sleeping is indicator. Education parents 1 is both low; education parents 2 is one low; both high educated is indicator. Ethnical origin parents 1 is one European Caucasian, one non- European Caucasian; ethnical origin parents 2 is both non-European Caucasian; both European Caucasian is indicator

\begin{tabular}{|c|c|c|c|c|c|c|c|c|}
\hline \multirow[t]{3}{*}{ Covariate } & \multicolumn{4}{|l|}{1} & \multicolumn{4}{|l|}{2} \\
\hline & \multirow[t]{2}{*}{ Significance } & \multirow[t]{2}{*}{ Odds ratio } & \multicolumn{2}{|c|}{$95.0 \%$ C.I. for $\mathrm{OR}$} & \multirow[t]{2}{*}{ Significance } & \multirow[t]{2}{*}{ Odds Ratio } & \multicolumn{2}{|c|}{$95.0 \%$ C.I. for OR } \\
\hline & & & Lower & Upper & & & Lower & Upper \\
\hline \multicolumn{9}{|l|}{ Genuine SIDS $(n=100)$} \\
\hline Prone sleeping & $<0.001$ & 14.4 & 5.69 & 36.6 & $<0.001$ & 100.0 & 40.8 & 245.5 \\
\hline Premature birth & 0.19 & 1.80 & 0.75 & 4.33 & & & & \\
\hline Gender & 0.49 & 1.28 & 0.64 & 2.58 & & & & \\
\hline Education parents & 0.29 & 1.68 & 0.64 & 4.42 & 0.75 & 1.19 & 0.42 & 3.39 \\
\hline Ethnical origin parents & 0.17 & 1.87 & 0.76 & 4.57 & 0.38 & 0.35 & 0.03 & 3.64 \\
\hline Lack of breastfeeding & 0.17 & 0.59 & 0.27 & 1.26 & & & & \\
\hline Maternal prenatal smoking & 0.99 & 1.00 & 0.33 & 3.08 & & & & \\
\hline Maternal postnatal smoking & 0.051 & 2.95 & 0.99 & 8.72 & & & & \\
\hline Paternal postnatal smoking & 0.08 & 2.00 & 0.92 & 4.35 & & & & \\
\hline \multicolumn{9}{|c|}{ SIDS with minor infection $(n=28)$} \\
\hline Prone sleeping & $<0.001$ & 49.2 & 13.1 & 184.4 & $<0.001$ & 173.8 & 37.9 & 795.4 \\
\hline Premature birth & 0.040 & 3.79 & 1.07 & 13.5 & & & & \\
\hline Gender & 0.23 & 0.45 & 0.13 & 1.64 & & & & \\
\hline Education parents & 0.81 & 1.21 & 0.25 & 5.80 & 0.80 & 0.79 & 0.14 & 4.67 \\
\hline Ethnical origin parents & 1.00 & 0.00 & & & 1.00 & 0.00 & & \\
\hline Lack of breastfeeding & 0.56 & 0.69 & 0.19 & 2.41 & & & & \\
\hline Maternal prenatal smoking & 0.95 & 1.06 & 0.18 & 6.18 & & & & \\
\hline Maternal postnatal smoking & 0.08 & 4.66 & 0.84 & 25.7 & & & & \\
\hline Paternal postnatal smoking & 0.26 & 1.97 & 0.60 & 6.44 & & & & \\
\hline
\end{tabular}

previous knowledge $[1,4,9-11,13-15,21,23,24]$. The importance of prone sleeping in SIDS is also indicated by the decline of the prevalence of SIDS in the Netherlands after introducing prone sleeping as a major risk factor for SIDS in the parental education programme in 1987 [9, 14]. Furthermore, the prevention system in the Netherlands is incorporated in the culture and does not depend on shortterm projects: consequently, advice against prone sleeping was given to all new parents from 1987 onwards. The continuing parents' motivation to put their child to sleep in prone position in spite of this advice remains a topic of discussion but addressing in detail would be beyond the scope of this study.

Our results also suggest that postnatal parental smoking currently poses a major risk factor for SIDS in the Netherlands. In the 1990s, some studies already reported the risk of postnatal parental smoking [5, 16]: however, these findings were criticised because they either inquired after smoking behaviour in the 2 weeks after the child was deceased (instead of the entire life span of the child) or they could not correct for the putative confounding effect of the socio-economic status [19]. Others have shown a doseresponse effect to passive smoking; however, this effect diminished after correcting for maternal prenatal smoking or socio-economic status [14]. In contrast, in the present study, it was clearly asked what the postnatal parental smoking habits were during the life of the child and not the habits at the time of the interview. Because in most other studies the effect of postnatal parental smoking was diminished after correction for prenatal maternal smoking or socio-economic status of the parents $[13-15,19]$, these factors were adjusted for in our multivariate analysis. Maternal smoking is a known risk factor for SIDS and mostly interpreted as a risk for the development of the unborn child caused by prenatal maternal smoking [1, 4, $10,11,14,15,19,21]$. Our data partly support these previous results as indicated by our finding that postnatal maternal smoking no longer reached statistical significance 
Table 6 Association of two histologically defined categories of SIDS with covariates compared to healthy, age-matched Dutch controls $(n=$ 2,841). $P$-values and odds ratios for the two largest SIDS categories defined by year of death. $P$-values calculated with two-tailed Fishers' exact test, OR and $95 \% \mathrm{CI}$ for OR of the binary logistic regression of all covariates. Prone sleeping 1 is primary prone sleeping; prone sleeping 2 is secondary prone sleeping; supine sleeping is indicator.
Postnatal smoking 1 is one parent smokes; postnatal smoking 2 is both parents smoke; no postnatal parental smoking is indicator. Education parents 1 is both low; education parents 2 is one low; both high educated is indicator. Ethnical origin parents 1 is one European Caucasian, one non-European Caucasian; ethnical origin parents 2 is both non-European Caucasian; both European Caucasian is indicator

\begin{tabular}{|c|c|c|c|c|c|c|c|c|}
\hline \multirow[t]{3}{*}{ Covariate } & \multicolumn{4}{|l|}{1} & \multicolumn{4}{|l|}{2} \\
\hline & \multirow[t]{2}{*}{ Significance } & \multirow[t]{2}{*}{ Odds ratio } & \multicolumn{2}{|c|}{$95.0 \%$ C.I. for $\mathrm{OR}$} & \multirow[t]{2}{*}{ Significance } & \multirow[t]{2}{*}{ Odds ratio } & \multicolumn{2}{|c|}{$95.0 \%$ C.I. for OR } \\
\hline & & & Lower & Upper & & & Lower & Upper \\
\hline \multicolumn{9}{|l|}{ SIDS 1996-2000 $(n=59)$} \\
\hline Prone sleeping & $<0.001$ & 22.6 & 9.59 & 53.3 & $<0.001$ & 115.6 & 46.5 & 287.3 \\
\hline Postnatal smoking & 0.07 & 2.24 & 0.94 & 5.38 & 0.009 & 5.41 & 1.52 & 19.25 \\
\hline Premature birth & 0.09 & 2.19 & 0.88 & 5.47 & & & & \\
\hline Gender & 0.57 & 0.81 & 0.39 & 1.67 & & & & \\
\hline Education parents & 0.34 & 0.65 & 0.27 & 1.57 & 0.19 & 0.52 & 0.19 & 1.40 \\
\hline Ethnical origin parents & 0.70 & 0.81 & 0.27 & 2.43 & 0.29 & 0.28 & 0.03 & 2.98 \\
\hline Lack of breastfeeding & 0.27 & 0.63 & 0.28 & 1.43 & & & & \\
\hline Maternal prenatal smoking & 0.47 & 1.49 & 0.51 & 4.44 & & & & \\
\hline \multicolumn{9}{|l|}{ SIDS 2001-2005 $(n=37)$} \\
\hline Prone sleeping & $<0.001$ & 21.8 & 7.41 & 64.2 & $<0.001$ & 82.9 & 25.2 & 272.6 \\
\hline Postnatal smoking & 0.051 & 2.87 & 0.99 & 8.29 & 0.01 & 6.62 & 1.58 & 27.8 \\
\hline Premature birth & 0.01 & 3.26 & 1.27 & 8.39 & & & & \\
\hline Gender & 0.34 & 1.57 & 0.65 & 3.79 & & & & \\
\hline Education parents & 0.11 & 2.83 & 0.78 & 10.3 & 0.76 & 1.26 & 0.29 & 5.52 \\
\hline Ethnical origin parents & 0.73 & 1.26 & 0.34 & 4.69 & 0.69 & 0.61 & 0.05 & 6.74 \\
\hline Lack of breastfeeding & 0.22 & 0.56 & 0.22 & 1.43 & & & & \\
\hline Maternal prenatal smoking & 0.97 & 0.98 & 0.29 & 3.29 & & & & \\
\hline
\end{tabular}

in the analysis where only the cases and controls that had reported negative for prenatal maternal smoking were included (Table 3). In contrast, postnatal smoking by one or both parents and postnatal paternal smoking did remain statistically significantly associated with SIDS (Tables 2 and 3) in these analyses. Notably, maternal smoking, either pre- or postnatal, does not reach statistical significance in the era 2001-2005. This might be explained by the new tool the Dutch mid-wives were given to help pregnant women quit smoking in 2001[18], which consist of a course on how to motivate and help women quit smoking and materials to support those prospective mothers. This emphasises the role of the Dutch prevention system that educates all prospective and young parents about the risk factors of SIDS, regardless of educational background, ethnicity or other socio-economic confounders. This may also explain the non-significance of those factors in the present study. Our findings are in agreement with those of Blair et al. [3] who have shown an additional effect of postnatal tobacco smoke exposure and a dose-responsive effect that maintained statistical significance after correc- tion for socio-economic status and prenatal maternal smoking. Furthermore, a German study reported that in $43 \%$ of examined SIDS cases high levels of nicotine in the hair of the infants was found as a result of long-term postnatal exposure to cigarette smoke [2]. Notably, the American Academy of Paediatrics and the UK Department of Health are not yet convinced of the association between postnatal parental smoking and SIDS [15, 21]. Smoking by the father as risk factor for SIDS is also undervalued in the Dutch parental education programme. In the "sleep safely" checklist [8] that is handed out to young parents, 12 of the 15 items deal with sleeping position and bedding and only one refers to smoking. Our results advocate for a stronger focus on postnatal smoking. We therefore appreciate a recently started campaign to convince parents not to smoke near their children because of several health risks, SIDS being one of them [20].

Another environmental factor detected by our analyses as being associated to SIDS is premature birth. Nevertheless, this variable has been previously linked to other SIDS risk factors such as risk for infections or prone position [9] 
Table 7 Association of two histologically defined categories of SIDS with covariates compared to healthy, age-matched Dutch controls ( $n=$ 2,841). $P$-values and odds ratios for the two largest SIDS categories defined year of death. $P$-values calculated with two-tailed Fishers' exact test, OR and $95 \% \mathrm{CI}$ for OR of the binary logistic regression of all covariates. Prone sleeping 1 is primary prone sleeping; prone sleeping 2

\begin{tabular}{|c|c|c|c|c|c|c|c|c|}
\hline \multirow[t]{3}{*}{ Covariate } & \multicolumn{4}{|l|}{1} & \multicolumn{4}{|l|}{2} \\
\hline & \multirow[t]{2}{*}{ Significance } & \multirow[t]{2}{*}{ Odds ratio } & \multicolumn{2}{|c|}{ 95.0\% C.I. for OR } & \multirow[t]{2}{*}{ Significance } & \multirow[t]{2}{*}{ Odds ratio } & \multicolumn{2}{|c|}{$95.0 \%$ C.I. for $\mathrm{OR}$} \\
\hline & & & Lower & Upper & & & Lower & Upper \\
\hline \multicolumn{9}{|l|}{ SIDS 1996-2000 $(n=59)$} \\
\hline Prone sleeping & $<0.001$ & 22.08 & 9.35 & 52.2 & $<0.001$ & 115.7 & 46.8 & 285.9 \\
\hline Premature birth & 0.09 & 2.19 & 0.88 & 5.46 & & & & \\
\hline Gender & 0.59 & 0.82 & 0.39 & 1.69 & & & & \\
\hline Education parents & 0.35 & 0.67 & 0.27 & 1.59 & 0.19 & 0.52 & 0.19 & 1.38 \\
\hline Ethnical origin parents & 0.70 & 0.81 & 0.69 & 2.43 & 0.29 & 0.28 & 0.03 & 3.04 \\
\hline Lack of breastfeeding & 0.28 & 0.64 & 0.29 & 1.44 & & & & \\
\hline Maternal prenatal smoking & 0.69 & 1.28 & 0.38 & 4.35 & & & & \\
\hline Maternal postnatal smoking & 0.06 & 3.01 & 0.93 & 9.71 & & & & \\
\hline Paternal postnatal smoking & 0.07 & 2.04 & 0.94 & 4.45 & & & & \\
\hline \multicolumn{9}{|l|}{ SIDS 2001-2005 $(n=37)$} \\
\hline Prone sleeping & $<0.001$ & 17.8 & 5.73 & 55.4 & $<0.001$ & 80.9 & 24.5 & 266.8 \\
\hline Premature birth & 0.01 & 3.51 & 1.36 & 9.08 & & & & \\
\hline Gender & 0.47 & 1.39 & 0.57 & 3.41 & & & & \\
\hline Education parents & 0.13 & 2.71 & 0.74 & 9.90 & 0.74 & 1.28 & 0.29 & 5.62 \\
\hline Ethnical origin parents & 0.65 & 1.35 & 0.37 & 4.92 & 0.74 & 0.67 & 0.06 & 7.21 \\
\hline Lack of breastfeeding & 0.35 & 0.63 & 0.24 & 1.65 & & & & \\
\hline Maternal prenatal smoking & 0.81 & 0.84 & 0.21 & 3.38 & & & & \\
\hline Maternal postnatal smoking & 0.21 & 2.37 & 0.62 & 9.12 & & & & \\
\hline Paternal postnatal smoking & 0.02 & 3.19 & 1.20 & 8.47 & & & & \\
\hline
\end{tabular}

is secondary prone sleeping; supine sleeping is indicator. Education parents 1 is both low; education parents 2 is one low; both high educated is indicator. Ethnical origin parents 1 is one European Caucasian, one non-European Caucasian; ethnical origin parents 2 is both non-European Caucasian; both European Caucasian is indicator

Table 8 Raw numbers of occurrence of covariates in cases and controls. Occurrence covariate/number that answered the question

\begin{tabular}{|c|c|c|c|c|c|}
\hline \multirow{3}{*}{$\begin{array}{l}\text { Covariate } \\
\text { Year } \\
\text { Total }\end{array}$} & \multicolumn{4}{|l|}{ Cases } & \multirow{3}{*}{$\begin{array}{l}\text { Controls } \\
2002-2003 \\
2,841\end{array}$} \\
\hline & $1987-1990$ & $1991-1995$ & $1996-2000$ & $2001-2005$ & \\
\hline & 19 & 27 & 59 & 37 & \\
\hline Primary prone & $4 / 8$ & $11 / 15$ & $12 / 53$ & $9 / 36$ & $83 / 2,825$ \\
\hline Secondary prone & $0 / 8$ & $0 / 15$ & $15 / 53$ & $9 / 36$ & $27 / 2,825$ \\
\hline Premature & $3 / 8$ & $1 / 9$ & $10 / 50$ & $13 / 36$ & $317 / 2,809$ \\
\hline Male gender & $12 / 19$ & $16 / 27$ & $36 / 59$ & $17 / 37$ & $1,434 / 2,837$ \\
\hline Both parents low educated & - & - & $23 / 44$ & $18 / 27$ & $1,022 / 2,646$ \\
\hline One parent low educated & - & - & $8 / 44$ & $5 / 27$ & $827 / 2,646$ \\
\hline One parent non-European Caucasian & $0 / 3$ & $0 / 2$ & $5 / 50$ & $3 / 35$ & $341 / 2,570$ \\
\hline Both parents non-European Caucasian & $1 / 3$ & $1 / 2$ & $5 / 50$ & $2 / 35$ & $99 / 2,570$ \\
\hline Started breastfeeding & $2 / 2$ & - & $29 / 47$ & $19 / 34$ & $2,264 / 2,823$ \\
\hline Prenatal maternal smoking & $1 / 1$ & - & $16 / 46$ & $10 / 30$ & $376 / 2,814$ \\
\hline Postnatal smoking one parent & - & $0 / 1$ & $16 / 48$ & $14 / 35$ & $653 / 2,808$ \\
\hline Postnatal smoking both parents & - & $1 / 1$ & $13 / 48$ & $12 / 35$ & $260 / 2,808$ \\
\hline Postnatal maternal smoking & - & $1 / 1$ & $19 / 48$ & $16 / 34$ & $396 / 2,827$ \\
\hline Postnatal paternal smoking & - & $1 / 1$ & $23 / 46$ & $21 / 33$ & $792 / 2,818$ \\
\hline
\end{tabular}


and shares prenatal maternal smoking as a risk factor with SIDS. The latter is confirmed by our analysis considering those cases and controls where no prenatal maternal smoking was involved (Tables 2 and 3) as premature birth no longer reaches statistical significance in those analyses. Previous research has been inconsistent on lack of breastfeeding being a risk factor for SIDS [21]. With our study, we could not statistically confirm lack of breastfeeding as a risk factor for SIDS, although the raw percentages differ by $\sim 20 \%$ between cases and controls in the period 1996-2005. Unfortunately, we have little data on this risk factor from our cases (Tables 1 and 8). The control percentage of $80 \%$ is realistic because for over a decade about $75 \%$ of Dutch mothers start with breastfeeding [7].

As far as we know, only one study [13] has previously made a subdivision between SIDS and borderline SIDS based on histological findings. We made a subdivision of all our cases into four subgroups based on histological findings (Liebrechts-Akkerman et al., submitted for publication) to test for the confounding effect of specific risk factors. For instance, prematurely born infants and infants that have postnatal tobacco smoke exposure may be more prone to respiratory infections [19]. This hypothesis is supported by our data; in the small group of SIDS with minor infections $(n=28)$, postnatal smoking by both parents and premature birth are statistically significant, whereas in much larger genuine SIDS group $(n=100)$ only postnatal smoking of both parents reached statistical significance and no association with premature birth was found. Maternal postnatal smoking was borderline significant in the genuine SIDS cases. However, we were unable to determine how premature birth and minor infections relate to one another in increasing the risk of SIDS as we had no information if the controls had any infections or other health issues at the time of interview. Unfortunately, the two additional histological subgroups, SIDS+ and major infection subcategories, were too small to be adequately analysed.

\section{Conclusion}

We identified postnatal smoking of the parents as an important risk factor for SIDS after correcting for socioeconomic status and prenatal maternal smoking, with an increasing effect observed when both parents smoked. Furthermore, we demonstrated that postnatal smoking of the father poses a risk for SIDS. Overall, prone sleeping remains as the highest risk factor for SIDS in the Netherlands after more than 20 years of parental education as demonstrated by our data. Our results also highlight the effect of premature birth. However, this study also highlights that parental education on risk factors for SIDS remains a necessary task, even after its introduction decades ago. This should be expanded with an emphasis on avoiding parental smoking, including special attention to postnatal and paternal smoking. The discrepancies between the histologically defined SIDS subgroups and the possible relation between premature birth and minor infections, as indicated here, ask for further research. Finally, the risk factors investigated here do not explain all SIDS cases in our study; thus, more research into additional predispositions and potential covariates not considered in our study (e.g. type of beddings, pacifiers, birth rank, housing, day care) as well as putative genetic factors and their interactions remain necessary. A dedicated study investigating the genetic effects on SIDS in the case group included here is currently on the way.

Acknowledgements We thank G.A. de Jonge of the LWW and all pathologist for providing case information: J. Arends, M. Baldewijns, H. Beerman, P. Blok, R. Boorsma, J. Bovee, R. Breeuwsma, M. Brinkhuis, A. Croonen, C. van Dijk, R. Dutrieux, W. van Houten, C. van der Hulsbergen, F. ten Kate, W. Kwee, R. de Krijger, I. van Lijnschoten, J. van der Linde, E. van der Loo, A. Maes, J. Meijers, A. Mulder, P. Nikkels, Nijhuis, E. Ooms, E. de Ruijter, R. Schapers, S. Schoots, C. Seldenrijk, J. Smits, A. Timmer, N. Vandevijver, C. Wauters, P. Westenend, L. Wijnaendts and D. Willebrand. We are grateful to J. Eck for useful information on the "ouder en kind" parental education programme in Rotterdam, The Netherlands, and to J.W. Oosterhuis, Department of Clinical Pathology, Erasmus University Medical Centre Rotterdam for continuous encouragement and support in the last stage of this project. This study was financially supported in part by the Netherlands Forensic Institute and has received additional support from the Erasmus University Medical Centre Rotterdam.

Conflicts of interest None of the authors have a financial relationship with the organisation that sponsored the research.

Open Access This article is distributed under the terms of the Creative Commons Attribution Noncommercial License which permits any noncommercial use, distribution, and reproduction in any medium, provided the original author(s) and source are credited.

\section{References}

1. Alm B, Möllborg P, Erdes L, Pettersson R et al (2005) SIDS risk factors and factors associated with prone sleeping in Sweden. ADC-online. doi:10.1136/adc.2005.088328

2. Bajanowski T, Brinkmann B, Mitchell EA et al (2007) Nicotine and cotinine in infants dying from sudden infant death syndrome. Int J Leg Med. doi:10.1007/s00414-007-0155-9

3. Blair PS, Fleming PJ, Bensley D et al (1996) Smoking and the sudden infant death syndrome: results from 1993-5 case-control study for confidential inquiry into stillbirths and death in infancy. BMJ 313:195-8

4. Blair PS, Sidebotham P, Berry PJ et al (2006) Major epidemiological changes in sudden infant death syndrome: a 20-year population-based study in the UK. Lancet 367:314-9

5. Brooke H, Gibson A, Tappin D, Brown H (1997) Case-control study of sudden infant death syndrome in Scotland, 1992-5. BMJ 314:1516

6. Casparie M, Tiebosch ATMG, Burger G et al (2007) Pathology databanking and biobanking in The Netherlands, a central role for 
PALGA, the nationwide histopathology and cytopathology data network and archive. Cell Onco 29:19-24

7. Central Bureau of Statistics. Voorburg/Heerlen, The Netherlands. Available at: http://www.cbs.nl. Accessed last on January 9, 2011

8. Consument en Veiligheid ( Dutch Consumer Safety Institute). brochure veilig slapen (brochure safe sleeping). Available at: http://www.veiligheid.nl. Accessed last on August 28, 2007

9. de Jonge GA, Burgmeijer RJ, Engelberts AC et al (1993) Sleeping positions for infants and cot death in the Netherlands 1985-91. Arch Dis Child 69(6):660-3

10. Guntheroth W (1989) Crib death: the sudden infant death syndrome. Second revised edition. Futura, New York

11. Hunt CE (2005) Gene-environment interactions: implications for sudden unexpected death in infancy. Arch Dis Child 90:48-53. doi:10.1136/adc.2004.051458

12. Krous HF, Beckwith JB, Byard RW et al (2004) Sudden infant death syndrome and unclassified sudden infant deaths: a definitional and diagnostic approach. Pediatrics 114:234-8

13. L'Hoir MP, Engelberts AC, van Well GThJ et al (1998) Sudden unexpected death in infancy: epidemiologically determined risk factors related to pathological classification. Acta Paed 87:1279-87

14. L'Hoir MP, Engelberts AC, van Well GThJ et al (1998) Casecontrol study of current validity of previously described risk factors for SIDS in the Netherlands. Arch Dis Child 79:386-393

15. Mitchell EA (2007) Recommendations for sudden infant death syndrome prevention: a discussion document. Arch Dis Child 92:155-9
16. Mitchell EA, Ford RP, Stewart AW et al (1993) Smoking and the sudden infant death syndrome. Pediatrics 91:893-6

17. Ponsonby AL, Dywer T, Cochrane J (2002) Population trends in sudden infant death syndrome. Semin Perinatol 26(4):296-305

18. RIVM (The Dutch National Institute for Public Health and the Environment). http://www.rivm.nl/vtv/object_document/ o2966n19459.htm. Accessed on January 4, 2011

19. Spiers PS (1999) Disentangling the separate effects of prenatal and postnatal smoking on the risk of SIDS. Am J Epidemiol 147(7):603-6

20. STIVORO (Institute for Public Health and Smoking). http://www. rokennietwaardekleinebijis.nl ("smoking, not near the kid"). Accessed on May 27, 2010

21. Task Force on Sudden Infant Death Syndrome (2005) American Academy of Pediatrics policy statement. The changing concept of sudden infant death syndrome: diagnostic coding shifts, controversies regarding the sleeping environment, and new variables to consider in reducing risk. Pediatrics 116:1245-55. doi:10.1542/peds.2005-1499

22. Van Schaijk M, Lanting CI, van Wauwe JP et al. Peiling risicofactoren wiegendood bij zuigelingen November 2002-April 2003 [in Dutch]. TNO quality of life 2006. http://tno-kwaliteit-vanleven.adlibsoft.com/docs/1578.pdf. Accessed on July 20, 2009

23. Vennemann MMT, Bajanowski T, Brinkmann B et al (2009) Sleep environment risk factors for Sudden Infant Death Syndrome Study. Pediatrics 123:1162-70

24. Vennemann MMT, Findeisen M, Betterfaß-Bahloul T et al (2005) Modifiable risk factors for SIDS in Germany: results of GeSID. Acta Paed 94:655-60 